\title{
Thymic Stromal Lymphopoietin Promotes Proliferation and Contractility of Human Pulmonary Artery Smooth Muscle
}

Michael Thompson, BS ${ }^{1}$, Venkatachalem Sathish, PhD, ${ }^{1,2}$ Logan Manlove, BS ${ }^{1}$, Benjamin Roos, $\mathrm{BS}^{1}$, Bowen Wang ${ }^{1}$, Robert Vassallo, MD, ${ }^{3}$ Jordan Miller, PhD, ${ }^{4,2}$ Christina M. Pabelick, MD ${ }^{1,2}$, Y.S. Prakash, MD, $\mathrm{PhD}^{1,2}$

${ }^{1}$ Department of Anesthesiology and Perioperative Medicine, Mayo Clinic- Rochester, MN 55905, USA; ${ }^{2}$ Department of Physiology and Biomedical Engineering, Mayo Clinic - Rochester, MN 55905, USA; ${ }^{3}$ Department of Medicine, Mayo Clinic - Rochester, MN 55905, USA; ${ }^{4}$ Department of Surgery, Mayo Clinic - Rochester, MN 55905, USA

Short Title: TSLP and Pulmonary Artery

Keywords: Pulmonary Hypertension; Proliferation; Inflammation; Vasoconstriction; Remodeling

Word count: 4041

\section{Corresponding Author:}

Y.S. Prakash, MD, PhD

Professor of Anesthesiology and Physiology

Department of Anesthesiology and Perioperative Medicine

4-184 W Jos SMH

Mayo Clinic

200 First St SW

Rochester, MN 55905

5075389869 (phone)

5072557300 (fax)

prakash.ys@mayo.edu 


\begin{abstract}
Hypoxia is a well-recognized risk factor in several pulmonary vascular diseases including pulmonary hypertension $(\mathrm{PH})$. Furthermore, hypoxia-associated inflammatory changes enhance the structural and functional changes in the pulmonary artery (PA) of PH patients. Understanding the mechanisms that link hypoxia and inflammation, particularly early in disease, is key to development of novel therapeutic avenues for PH. Thymic stromal lymphopoietin (TSLP) is an "early" inflammatory mediator thought to be critical in diseases such as asthma, chronic obstructive pulmonary disease and atopic dermatitis. TSLP has canonical effects on the immune system, but can also have non-canonical effects on resident lung cells, e.g. airway smooth muscle. Currently, the expression and role of TSLP in the PA is unknown. We hypothesized that locallyproduced TSLP potentiates the effects of hypoxia in PA remodeling and contractility relevant to PH. Experiments in human PA endothelial cells (PAECs) and smooth muscle cells (PASMCs) found PAECs to be a larger source of TSLP which targets PASMCs to enhance intracellular $\mathrm{Ca}^{2+}$ responses to vasoconstrictor agonist as well as cell proliferation, acting via a number of signaling cascades including Stat3 and PI3/Akt. Hypoxia, acting via HIF1 $\alpha$, enhanced PAEC production of TSLP, and promoted TSLP effects on PASMCs. Interestingly, TSLP per se enhance HIF1 $\alpha$. Overall, these novel data highlight a role for TSLP in hypoxia effects on the PA, and thus relevance for inflammation in $\mathrm{PH}$.
\end{abstract}




\section{Introduction}

Thymic stromal lymphopoietin (TSLP) is an IL-7-like cytokine first identified in the thymus as a factor in T and B cell development,[1-3] but now found to be produced by a variety of non-thymic cell types including epithelial cells of the lung, gut and skin, fibroblasts, and circulating and tissue immune cells, particularly dendritic cells.[2, 4, 5] Acting via a heterodimeric complex of its receptor TSLP-R and IL7R $\alpha$, TSLP serves as an interface between the environment and the body to skew the immune response towards a Th2 phenotype early during the response to allergic and other stimuli $[6,7]$ : an effect that has driven the high interest in TSLP in atopic dermatitis, allergic asthma, and non-infectious GI disorders.[3, 8-11] In spite of such interest, there are currently significant knowledge gaps in TSLP expression and signaling patterns (particularly given species and cell type differences).

The relevance of TSLP to the pulmonary vasculature lies in the role of inflammation in diseases such as pulmonary hypertension $(\mathrm{PH})$. While different types of $\mathrm{PH}$ differ in etiology, risk factors and presentations, there are two factors that may be important across multiple PH groups: hypoxia and inflammation. Hypoxia is certainly a key aspect of Group III PH, and can also be contributory in Group IV. $[12,13]$ In addition, there is increasing evidence that inflammation also plays a significant role in $\mathrm{PH}$ pathogenesis and exacerbation, and is likely important not only in Group III, but also Group I and IV.[14, 15] In this regard, hypoxia can influence the inflammatory response with subsequent effects on PA structure and function.[16-18] For example, in highaltitude mountain sickness,[19, 20] circulating levels of pro-inflammatory cytokines are increased. In healthy persons, hypoxia increases serum IL-6, and C-reactive protein as well IL-6 receptor levels.[21-23] In mice, even short-term hypoxia leads to vascular leakage, inflammatory cell infiltrates and elevated serum cytokines.[24, 25] There is strong circumstantial evidence for an 
inflammatory pathogenesis of $\mathrm{PH}[24,26-28]$. Furthermore, $\mathrm{PH}$ is associated with inflammatory conditions including rheumatoid arthritis, lupus, and collagen vascular diseases.[24, 29, 30]

The significance of understanding the mechanisms by which hypoxia induces inflammation is clear. While such mechanisms may vary in different forms of $\mathrm{PH}$, what is important to recognize is that if we can identify early mediators of the inflammatory response to hypoxia, then novel preventive and therapeutic avenues can be explored. Here, given the increasing recognition that TSLP is an early respondent and inflammatory mediator in other organ systems, we believe that the TSLP/TSLP-R signaling cascade is a novel target to explore in PH, especially given the potential that TSLP may have pleiotropic effects relevant to PH pathophysiology. Furthermore, the information derived from our studies has the potential to target other disease conditions where the hypoxia-inflammation axis is important, including lung injury especially following transplantation. Accordingly, in the current study, we explored the potential role of TSLP in the human pulmonary artery (PA) as a first step towards understanding the contribution of TSLP to PH. We hypothesized that TSLP represents a locally-produced inflammatory mediator in the PA, with autocrine/paracrine effects on the endothelium and smooth muscle. 


\section{Materials and Methods}

\section{Culture of Human Pulmonary Artery Endothelial Cells (PAECs) and Smooth Muscle Cells} (PASMCs)

Human PAECs and PASMCs were obtained from commercial sources (Thermo Fisher Scientific, Waltham, MA and ATCC, Manassas, VA) or, under a Mayo Institutional Board-approved protocol conforming with the Declaration of Helsinki. Cells were isolated from PA of lung samples incidental to patient thoracic surgery at Mayo Clinic-Rochester (lobectomies, pneumectomies for non-PH transplant indications and focal non-infectious indications such as localized tumors) as previously described [31-33]. Since samples were obtained post-hoc incidental to surgery and not for the purpose of this research per se, and furthermore patient care was unaffected by any studies performed with such samples, the protocol was considered not Human Subjects research and exempt by Mayo IRB (minimal risk protocol).

Sample collection was limited to normal appearing areas of the vasculature identified by the pathologist and verified under gross microscopy. Samples were de-identified and were considered not Human Subjects Research (minimal risk protocol). The PA was transported rapidly to the laboratory in ice-cold Hank's Balanced Salt Solution (HBSS), cleaned and the endothelium separated, with adventitia removed for further cell isolation.

For PASMCs, endothelium-denuded tissue was minced and placed in $100 \mathrm{~mm}$ petri dishes with DMEM F12 containing 10\% FBS/1\% ABAM. Tissue explants were maintained for 5-7 days at $37^{\circ} \mathrm{C}$ in $95 \%$ air $/ 5 \% \mathrm{CO}_{2}$ after which the source tissue was removed, cells grown to confluence for experiments, plated in $60 \mathrm{~mm}$ dishes (Western analysis), 8 well Lab-Tek culture chambers or 96 well plates (proliferation assays).

PAECs were isolated via modification of methods described previously.[31, 34] Briefly, endothelium from PA was minced with a razor blade and incubated in Earle's Balanced Salt 
Solution (EBSS) containing 0.1\% Collagenase II and $0.25 \mathrm{U} / \mathrm{ml}$ Dispase (Thermo) for $30 \mathrm{~min}$ at $3^{\circ} \mathrm{C}$ with continuous agitation. DNase I ( $7.5 \mu \mathrm{g} / \mathrm{ml}$ final concentration, Sigma, St. Louis, MO) was then added and tissue incubated for another $30 \mathrm{~min}$ at $37^{\circ} \mathrm{C}$. Dissociated cells were separated from undigested tissue using a $100 \mu \mathrm{m}$ strainer and pelleted at $400 x \mathrm{x}$ for 5 minutes. Cells were resuspended in PBS and subsequently incubated with anti-CD45 and anti-CD31 microbeads (Miltenyi Biotec, Inc, Auburn, CA) and endothelial cells magnetically separated using the AutoMacs Pro cell separation system (Miltenyi) according to manufacturer's protocol. Final cell pellet was resuspended in Endothelial Cell Growth Medium-2 (EGM-2, Lonza, Walkersville, MD), plated in $75 \mathrm{~cm}^{2}$ flasks and grown to confluence.

Prior to experimentation, PAECs and PASMCs were serum-deprived for $24 \mathrm{~h}$ and all cells were used between passages 1 and 5. PAEC and PASMC phenotype was verified by immunostaining using anti-CD31 (Abcam, Cambridge, MA; ab24590) or smooth muscle specific anti-smooth muscle actin (Sigma, St. Louis, MO; A2547) primary antibodies, respectively.

\section{Cell Exposures}

Human PAECs and PASMCs were incubated for $72 \mathrm{~h}$ at $37^{\circ} \mathrm{C}$ in normoxia $\left(21 \% \mathrm{O}_{2}\right)$ or hypoxia $\left(1 \% \mathrm{O}_{2}\right)$ in serum free medium (control), supplemented as appropriate with $20 \mathrm{ng} / \mathrm{ml}$ recombinant human TSLP (R\&D Systems, Minneapolis, MN). The role of HIF-1 $\alpha$ was verified using $10 \mu \mathrm{M}$ (final concentration) of HIF-1 pharmacological inhibitor (Santa Cruz Biotechnology, Inc., Dallas, TX). The functional activity of TSLP was inhibited with the use of $10 \mu \mathrm{M}$ STAT-3 Inhibitor, LLL12 (EMD Millipore, Billerica, MA). Inhibitors were incubated with cells $1 \mathrm{~h}$ prior to adding TSLP.

\section{Immunostaining}


PAECs and PASMCs were seeded in 8 well Lab-Teks (Thermo) at 5,000 cells/well. Cells were fixed in 4\% paraformaldehyde for $15 \mathrm{~min}$ and washed with TBS. For detection of TSLP cells were permeabilized for $10 \mathrm{~min}$ in TBS containing $0.1 \%$ Triton X-100. Detection of TSLP-R did not require permeabilization. Cells were then blocked for $1 \mathrm{~h}$ in TBS containing $4 \%$ normal donkey serum and incubated for $1 \mathrm{~h}$ at room temperature with $5 \mu \mathrm{g} / \mathrm{ml}$ primary antibody (TSLP, Santa Cruz, sc-33791; TSLP-R, Santa Cruz, sc-83871). Samples were then washed with TBS and incubated with donkey anti-rabbit Alexa 555 secondary antibody (1:500, Thermo) for $1 \mathrm{~h}$ at room temperature, washed with TBS and coverslips mounted with Flurogel II containing DAPI (Electron Microscope Sciences, Hatfield, PA). Cells were visualized using a Nikon Eclipse TE2000-U microscope with a 40x/1.30 NA oil objective lens.

\section{Assessment of TSLP Levels}

Cell culture supernatants from PAECs and PASMCs grown on 60mm petri dishes and exposed to normoxia or hypoxia, were concentrated using Ultracel 3k Amicon Ultra centrifugal filters (EMD Millipore) and assayed for TSLP via ELISA (R and D Systems, Minneapolis, MN) according to manufacturer's protocol, and as described previously for airway cells.[5] Changes in optical density were determined using a FlexStation3 microplate reader (Molecular Devices, Sunnyvale, CA) set to $450 \mathrm{~nm}$ (wavelength correction set to $540 \mathrm{~nm}$ ) and compared to manufacturer-provided calibration curve.

\section{Western Analysis}

Standard SDS-PAGE (Criterion Gel System; Bio-Rad, Hercules, CA; 4-15\% gradient gels) and Trans-Blot Turbo transfer system using nitrocellulose membranes (Bio-Rad) were used. Membranes were blocked with LiCor blocking buffer (LiCor, Inc., Lincoln, NE) for 1h at room temperature prior to addition of primary antibody $(1 \mu \mathrm{g} / \mathrm{mL}$ rabbit anti-TSLP-R, sc-83871,Santa 
Cruz; $1 \mu \mathrm{g} / \mathrm{mL}$ rabbit anti-TSLP, sc-33791, Santa Cruz;1 $\mu \mathrm{g} / \mathrm{mL}$ rabbit anti-ERK, sc-94, Santa

Cruz; rabbit anti-PI3K, 1:500, 06-195, EMD Millipore; $1 \mu \mathrm{g} / \mathrm{ml}$ rabbit anti-Akt, , 4691, Cell

Signaling Technologies, Inc, Danvers, MA; $2 \mu \mathrm{g} / \mathrm{mL}$ rabbit anti-Cyclin E, sc-25303, Santa Cruz;

$2 \mu \mathrm{g} / \mathrm{mL}$ rabbit anti-PCNA, sc-25280, Santa Cruz; $2 \mu \mathrm{g} / \mathrm{mL}$ rabbit anti-JAK2, sc-294, Santa Cruz;

$2 \mu \mathrm{g} / \mathrm{mL}$ rabbit anti-STAT3, sc-482, Santa Cruz ; 1 $\mu \mathrm{g} / \mathrm{ml}$ rabbit anti-GAPDH, 2218, Cell

Signaling) overnight at $4^{\circ} \mathrm{C}$ with gentle rocking. Membranes were washed in TBS, incubated with goat anti-rabbit or anti-mouse secondary antibodies (IRdye800, 1:10,000 dilution, LiCor) for $1 \mathrm{~h}$ at room temperature. Blots were visualized and densitometry performed with an Odyssey infrared imaging system (Li-Cor Biosciences).

\section{Cell Proliferation Assay}

Proliferation of PASMCs was assayed at $72 \mathrm{~h}$ (with or without preceding interventions) using the CyQuant NF kit (Invitrogen) according to manufacturer's protocol. Cells were first washed with HBSS and exposed to the CyQuant dye for $1 \mathrm{~h}$ at room temperature. Dye binding to DNA (fluorescence) was measured on the FlexStation3 microplate reader. Dye calibrations were performed empirically using different cell counts to establish a standard curve and fluorescence converted to cell number to determine degree of proliferation.

\section{Real Time Calcium Imaging}

We have previously described the techniques for real-time fluorescent imaging of $\left[\mathrm{Ca}^{2+}\right]_{\mathrm{i}}$ using $5 \mu \mathrm{M}$ Fura-2/AM [31, 35]. Following dye loading for 45 minutes at room temperature, cells were visualized using a Nikon TE2000-U inverted microscope and Nikon Elements imaging software. Cells were initially perfused with $\mathrm{HBSS}$ containing $2 \mathrm{mM} \mathrm{CaCl} \mathrm{Cl}_{2}$ to establish a baseline then perfused with $10 \mu \mathrm{M}$ serotonin. $\left[\mathrm{Ca}^{2+}\right]_{\mathrm{i}}$ responses from 20 regions of interest were obtained from multiple cells per chamber. 


\section{Statistical Analysis}

All experiments were performed in cells from 4-8 different artery (patient) samples (n values are indicated for each experiment in the results). Not all protocols were performed in each sample although a minimum of 4 different samples was used for each experiment. For box plots, both median (solid line) and mean (dashed line) are indicated. Analysis of results was accomplished using one-way ANOVA with repeated measures or Tukey post-hoc analysis where appropriate. Statistical significance was set at $\mathrm{p}<0.05$; all values are expressed as means $\pm \mathrm{SE}$. 


\section{Results}

TSLP and TSLP-R expression and secretion in human PA. Immunofluorescence staining of human PAECs and PASMCs for TSLP and TSLP-R showed the presence of TSLP and TSLP-R in both cell types (Figure 1A). Extracellular TSLP measured by ELISA demonstrated that PAECs release TSLP $(110 \pm 24 \mathrm{pg} / \mathrm{ml}$ at normoxia), and such release was significantly enhanced (252+91 $\mathrm{pg} / \mathrm{ml}$ ) following $72 \mathrm{~h}$ hypoxia $(\mathrm{p}<0.05$ compared to normoxia control; $\mathrm{n}=8$ ). However, hypoxia did not appear to influence PASMC TSLP release $(68+8$ and $80 \pm 15 \mathrm{pg} / \mathrm{ml}$, respectively; $\mathrm{n}=5)$ (Figure 1B): levels that were lower than those shown by PAECs.

TSLP and TSLP-R protein expression in human PAEC and PASMC. Western Blot analysis using anti-human TSLP antibody demonstrated TSLP-R expression in both human PAECs and PASMCs . TSLP protein levels in PAECs were significantly increased (+78\%) following hypoxia exposure compared to normoxia controls $(\mathrm{p}<0.05 ; \mathrm{n}=4)$. In contrast to PAECs, intracellular expression of TSLP in PASMCs was not significantly changed after 72h exposure to hypoxia $(\mathrm{n}=4)$

(Figure 2A). Western analysis from human PAEC and PASMC showed expression of TSLP-R and significant upregulation in both cell types following $72 \mathrm{~h}$ hypoxia compared to normoxia controls $(\mathrm{p} \leq 0.05 ; \mathrm{n}=4)$ (Figure 2B).

TSLP enhances human PASMC proliferation. Based on our data suggesting that TSLP, particularly under hypoxia, derives from PAECs, we explored the idea that such TSLP targets PASMCs, and thus focused the remainder of the study on this cell type. PASMCs were seeded into 96 well plates with approximately 10,000 cells/well and proliferation experiments conducted using the CyQuant fluorescent assay. Serum-deprived PASMCs showed baseline proliferation of 10\% over a $72 \mathrm{~h}$ period compared to time zero. Human PASMCs exposed to 20ng/ml TSLP showed significantly greater proliferation $(+27 \%)$ compared to baseline controls. Hypoxia alone also 
enhanced human PASMC proliferation $(+69 \%)$, although TSLP in combination with hypoxia had no significant additional effect on proliferation. HIF inhibitor significantly blunted effects on proliferation with hypoxia exposure and in the presence of hypoxia and TSLP (-39\% and $-54 \%$, respectively). The effectiveness of the HIF inhibitor was confirmed via immunostaining by prevention of HIF-1 $\alpha$ translocation to the nucleus (data not shown). Furthermore, pre-treatment of PASMC with LLL12 (STAT3 inhibitor) also inhibited PASMC proliferation with hypoxia and the presence or absence of TSLP $(\mathrm{p}<0.05, \mathrm{n}=4)$ (Figure 3$)$.

Proliferation was further verified by Western Blot analysis of human PASMCs for proliferating cell nuclear antigen (PCNA) or Cyclin E protein expression following exposure to TSLP or hypoxia, both demonstrating enhanced PCNA $(+89 \%$ with TSLP and $+135 \%$ with hypoxia) and Cyclin E ( $+165 \%$ with TSLP and $+115 \%$ with hypoxia) expression compared to normoxia controls. TSLP had no significant additional effect on expression of PCNA or Cyclin E in the presence of hypoxia. Interestingly, the HIF inhibitor significantly blunted Cyclin E expression in the presence of TSLP during normoxia as well as during hypoxia exposure (-40\%). The STAT3 inhibitor, LLL12, significantly reduced Cyclin E expression levels with TSLP treatment in both normoxia and hypoxic conditions (-60\% each compared to respective controls). PCNA expression was also significantly inhibited by LLL12 with hypoxia and TSLP treatment ($43 \%$ ) but was not substantially effected during normoxia ( $<<0.05, n=5$ each) (Figure 4$)$.

Mechanisms of TSLP action in human PASMC. MAPK and PI3K/Akt pathways are known to be involved in PA cell proliferation in response to mitogens, thus we investigated the possible link between these pathways with TSLP and hypoxia. Western blot analysis of human PASMCs exposed to normoxia or hypoxia in the presence or absence of $20 \mathrm{ng} / \mathrm{ml}$ TSLP for $72 \mathrm{~h}$ demonstrated no significant change in the expression of ERK1 and ERK2 with hypoxia compared to normoxia. 
Inhibition of STAT3 significantly blunted ERK1/2 expression (-61\% and $-64 \%$ respectively) under hypoxic conditions and in the presence of TSLP compared to hypoxia+TSLP. Similar trends are observed with LLL12 treatment in normoxia but are not statistically significant. In comparison, PI3K and Akt expression were considerably increased $(+125 \%$ and $+131 \%)$ in the presence of TSLP compared to normoxia controls. Additionally, hypoxia also significantly increases expression of PI3K $(+240 \%)$ and Akt (+228\%). HIF inhibition significantly prevented upregulation of Akt (-58\%) when exposed to hypoxia and TSLP and blunted PI3K expression when incubated with TSLP in normoxia (-52\%) and hypoxia (-68\%). STAT3 inhibition with LLL12 substantially reduced PI3K expression (-49\%) with TSLP and hypoxia ( $<<0.05, \mathrm{n}=5-6)$ (Figure 5). Overall, these data suggested several common mechanisms where TSLP and hypoxia intersect.

TSLP enhances Jak/STAT pathway protein expression in human PASMC. To further delineate the downstream functions of TSLP in human PASMC, we next investigated a known TSLP activated pathway in other cell types: Jak2/STAT3 pathway. Western blot analysis of human PASMCs exposed to normoxia or hypoxia for $72 \mathrm{~h}$, with or without TSLP, showed that hypoxia enhances Jak2 expression (+97\%) compared to normoxia control. TSLP increased Jak2 expression $(+53 \%)$ in normoxic conditions but did not potentiate the effects of hypoxia. HIF inhibitor and LLL12 significantly decreased Jak2 expression in the presence of TSLP during normoxia (-38\% and $-58 \%$, respectively), but only LLL12 treatment caused significant downregulation $(-73 \%)$ of Jak2 compared to combined TSLP and hypoxia exposure. $(\mathrm{p}<0.05, \mathrm{n}=6)$ (Figure 6A). In comparison, Western analysis of STAT3 expression shows significant increase with TSLP treatment $(+115 \%)$ in normoxia and hypoxia $(+145 \%)$ alone when compared to 
normoxia controls. HIF inhibitor (-67\%) and LLL12 (-70\%) significantly decrease the effect of TSLP during hypoxic exposures. $(\mathrm{p}<0.05, \mathrm{n}=6)$ (Figure 6B)

Effect of TSLP and hypoxia on $\left[\mathrm{Ca}^{2+}\right]_{i}$ in human PASMC. Enhanced contractility is known to occur in PA during hypoxia or PH; therefore, we examined the role of hypoxia and TSLP on $\left[\mathrm{Ca}^{2+}\right]_{\mathrm{i}}$ responses to serotonin in human PASMCs. Exposure to 20ng/ml TSLP for $72 \mathrm{~h}$ significantly increased the amplitude of serotonin responses in PASMCs $(627 \pm 29 \mathrm{nM})$ compared to normoxia controls $(362 \pm 15 \mathrm{nM})$, an effect which was inhibited by HIF inhibitor (493+36 nM). Hypoxia alone significantly increased $\left[\mathrm{Ca}^{2+}\right]_{\mathrm{i}}$ responses to serotonin $(501 \pm 24 \mathrm{nM})$ which was potentiated in the presence of TSLP $(700 \pm 41 \mathrm{nM})$, but blunted by HIF inhibitor $(399 \pm 38 \mathrm{nM})(\mathrm{p}<0.05, \mathrm{n}=4)$ (Figure 7). 


\section{Discussion}

In spite of substantial medical advances, $\mathrm{PH}$ remains a devastating disease. Although multifactorial in etiology, chronic hypoxia is a well-recognized risk factor and pathophysiologically relevant mechanism in several forms of PH. Furthermore, hypoxia can induce inflammation that only enhances the detrimental structural and functional changes in the PA. Accordingly, understanding the mechanisms that link hypoxia and inflammation, particularly early in disease, is important. In skin and airway disease, there is increasing recognition that TSLP is a locally-produced, critical, early factor that drives the inflammatory cascade relevant to allergy, asthma and chronic obstructive pulmonary disease, and furthermore has non-canonical effects on airway structure and function. Therefore, we hypothesized that locally-produced TSLP mediates and potentiates the effects of hypoxia on PA remodeling and contractility via TSLP receptors present in the PA.

Pulmonary artery endothelial cells regulate both PA structure and function, e.g. via the well-known release of NO towards vasodilation and endothelin towards vasoconstriction and remodeling. The endothelium certainly experiences alterations in oxygen levels and thus plays a major role in mediating and modulating the effects of hypoxia in pathogenesis of diseases such as pulmonary hypertension. Accordingly, understanding endothelial mechanisms that are altered by hypoxia becomes important. While hypoxia can influence the PAEC in several ways, the idea that locally-produced pro-contractile or pro-proliferative factors permits exploration of the concept that such mechanisms can contribute to induction and maintenance of disease. For example, we had previously shown that in response to hypoxia, human PAECs can release the neurotrophin BDNF which can enhance PASMC contractility [31]. In this regard, the effects of hypoxia on endothelial TSLP have interesting parallels. On the other hand, BDNF also enhances endothelial NO [36] and 
may thus serve a different purpose in the PA. However, similar to our finding of TSLP effects in PASMCs, BDNF has autocrine effects on PAECs [32] where it modulates HIF1 $\alpha$ thus priming PAECs in their response to hypoxia. Whether a similar autocrine influence of TSLP occurs in PAECs is not known, and was not examined in the present study. However, the presence of TSLP$\mathrm{R}$ on PAECs may allow for such effects. What remains to be then examined is whether in the context of hypoxia, overall TSLP effects on the PA would result in vasodilation (e.g. via NO) or vasoconstriction due to the effects of TSLP on PASMC calcium responses, as observed in the current study.

Within the PA, smooth muscle cells also play important structural and functional roles through effects on vascular tone and contractility, as well as vascular stiffness and fibrosis via cell proliferation and production of extracellular matrix. Accordingly, mechanisms derived from PAECs as well as PASMCs can have substantial local influences on the smooth muscle in acute and chronic conditions. Here, we demonstrate that TSLP is secreted by both PAECs and PASMCs, although it appears that PAECs are a more substantial source, and importantly it is PAEC-derived TSLP that is upregulated under hypoxic conditions. Thus, we propose that PASMC-derived TSLP may represent a "background" level with perhaps autocrine/paracrine effects. What then becomes important are the effects of TSLP on PASMCs, and our current results show contributions to enhanced PASMC proliferation and contractility, particularly in hypoxia.

The effects of TSLP on PASMCs involve the receptor TSLP-R which is abundantly present in smooth muscle. Interestingly, hypoxia, acting via HIF-1 $\alpha$ upregulates TSLP-R, pointing to at least one mechanism by which hypoxia and TSLP could interact, particularly given the additional observation of increased TSLP production by PAECs in hypoxia.

There is currently little information on how hypoxia may regulate TSLP or TSLP-R in any 
tissue. Data from skin, airways and GI suggest that TSLP regulation is highly cell-type specific (e.g. constitutive vs. induced, responsiveness to specific cytokines such as TNF- $\alpha$, IL-1) [5, 6, 11]. Even in these systems, much of the information is from cellular mRNA, with substantially less data on TSLP secretion which is required for autocrine/paracrine function. Nonetheless, promoters for HIF-1 $\alpha$ have been identified on the TSLP gene,[35, 37, 38] and some studies have shown ERK1/2 mediated alterations in TSLP expression[35, 39] during inflammation. In terms of TSLP$\mathrm{R}$, there is even less information on its regulation, but a weak HIF-1 $\alpha$ promoter is recognized, while the role of other transcription factors is not known. In non-vascular systems TSLP expression can be enhanced in a HIF-1 $\alpha$ dependent manner[40] and is consistent with the presence of the promoters. Our studies showing the suppressing effect of HIF-1 $\alpha$ inhibitor on TSLP or TSLP-R expression are consistent but further exploration on such regulation is needed. Furthermore, it would be important to determine whether baseline TSLP/TSLP-R expression is different, or differently influenced by hypoxia in patients with $\mathrm{PH}$, especially if mechanisms such as HIF-1 $\alpha$ are involved.

PH represents both an imbalance between the extent of vasodilation and vasoconstriction, as well as PA remodeling, and the latter involves PAEC and PASMC proliferation and migration, resulting in dysfunctional endothelial and smooth muscle. In vitro, PASMCs and PAECs can proliferate in response to multiple signals. JAKs are involved in such mitogen-induced signaling in human PA $[35,41]$ Additionally, ERK and PI3K pathways, as well as Rac1, are also important in PA cell proliferation induced by mitogens $[35,42,43]$. These signaling pathways involved in mitogen-induced PA cell proliferation happen to be also involved in TSLP signaling, at least in other non-vascular systems. For example, TSLP induces cell proliferation of the human myeloid leukemia cell line MUTZ-3 via STAT5 phosphorylation [44]. In human airway smooth muscle, 
we previously showed that STAT5 is activated by TSLP.[5] Similarly, in human airway epithelial cells, MAPK, PI3/Akt and NFאB are all activated by TSLP $[45,46]$. The present results showing increase expression of PI3/Akt are entirely consistent in this regard. One report did show that phosphorylation of JAK 1 and 2 precedes STAT3 phosphorylation upon TSLP-TSLP-R binding in human lymphoid cells [44]. Indeed, it is likely that the range of signaling mechanisms activated by TSLP is species-, cell- and perhaps context-dependent. Nonetheless, the role of these signaling intermediates in TSLP effects on PASMC was previously unknown, especially in the presence of hypoxia or underlying PH. What makes TSLP particularly relevant is the increasing interest in STAT inhibitors for a number of diseases such as fibrosis.[47]

An interesting observation in our studies was that even under normoxic conditions, inhibition of HIF-1 $\alpha$ resulted in blunting of TSLP effects in PASMCs, for example on intracellular calcium signaling. These data suggest that TSLP may prime PASMCs for hypoxia effects. In this regard, the baseline expression and secretion of TSLP by PASMCs (or PAECs) may play such an autocrine role. While we did not observe a synergistic effect of TSLP and hypoxia on different parameters, we also point out the extremely potent level of hypoxia and the extended duration of exposure in these initial studies. Further exploration using different hypoxia and TSLP exposures are needed to determine the functional significance of TSLP effect on HIF-1 $\alpha$.

In addition to effects on cell proliferation, we observed that TSLP enhances $\left[\mathrm{Ca}^{2+}\right]_{\mathrm{i}}$ in PASMCS. Vasoconstriction involves increased $\left[\mathrm{Ca}^{2+}\right]_{i}$ and contractility of PASMCs, which may be mediated by a number of regulatory mechanisms, particularly $\mathrm{Ca}^{2+}$ influx mechanisms such as store-operated entry and voltage-gated channels, as well as intracellular $\mathrm{Ca}^{2+}$ release from sarcoplasmic reticulum, and enhanced $\mathrm{Ca}^{2+}$ sensitivity for force generation, partially involving the RhoA/Rho kinase pathway [48, 49]. Previous studies have already shown the importance of 
enhanced constrictive but blunted dilatory mechanisms in mediating the effects of hypoxia in the $\mathrm{PA}$, as well as their contribution of $\mathrm{PH}$ pathophysiology. Our results suggest a central role for TSLP (e.g. that derived from PAECs) in hypoxia-induced modulation of $\left[\mathrm{Ca}^{2+}\right]_{\mathrm{i}}$ and contractility in PASMCs. There is currently little information on such effects of TSLP in any vascular system. However, in recent studies using human airway smooth muscle, we demonstrated that TSLP can enhance $\left[\mathrm{Ca}^{2+}\right]_{\mathrm{i}}$ responses to agonist, at least via increased $\mathrm{Ca}^{2+}$ influx.[5] Whether TSLP influence RhoA/Rho kinase and $\mathrm{Ca}^{2+}$ sensitivity is unknown in PA and will be explored in future studies.

In conclusion, our study demonstrates that local production of TSLP occurs in the PA, largely involving PAECs, while PASMCs which express TSLP-R are responsive. Hypoxia enhances local TSLP production and PASMC TSLP-R expression leading to effects on PASMC proliferation and enhancement of $\left[\mathrm{Ca}^{2+}\right]_{i}$. As both TSLP production and TSLP-R expression are enhanced with hypoxia, the present study suggests that TSLP may play a role in hypoxia induced diseases including $\mathrm{PH}$.

Sources of Funding: This work was supported a grant from the Mayo Center for Biomedical Discovery (CBD; Prakash).

Conflict of Interest: None declared. 


\section{References.}

1. Levin SD, Koelling RM, Friend SL, Isaksen DE, Ziegler SF, Perlmutter RM, et al. Thymic stromal lymphopoietin: A cytokine that promotes the development of IgM+ B cells in vitro and signals via a novel mechanism. J Immunol. 1999;162(2):677-83.

2. Soumelis V, Reche PA, Kanzler H, Yuan W, Edward G, Homey B, et al. Human epithelial cells trigger dendritic cell mediated allergic inflammation by producing TSLP. Nat Immunol. 2002;3(7):673-80. Epub 2002/06/11. doi: 10.1038/ni805. PubMed PMID: 12055625.

3. Lee EB, Kim KW, Hong JY, Jee HM, Sohn MH, Kim KE. Increased serum thymic stromal lymphopoietin in children with atopic dermatitis. Pediatr Allergy Immunol. 2010;21(2 Pt 2):e457-60. Epub 2010/05/07. doi: 10.1111/j.1399-3038.2009.00919.x. PubMed PMID: 20444170.

4. Gilliet M, Soumelis V, Watanabe N, Hanabuchi S, Antonenko S, de Waal-Malefyt R, et al. Human dendritic cells activated by TSLP and CD40L induce proallergic cytotoxic T cells. J Exp Med. 2003;197(8):1059-63. PubMed PMID: 12707303.

5. Smelter DF, Sathish V, Thompson MA, Pabelick CM, Vassallo R, Prakash YS. Thymic stromal lymphopoietin in cigarette smoke-exposed human airway smooth muscle. J Immunol. 2010;185(5):3035-40. PubMed PMID: 20660708.

6. Cianferoni A, Spergel J. The importance of TSLP in allergic disease and its role as a potential therapeutic target. Expert Rev Clin Immunol. 2014;10(11):1463-74. Epub 2014/10/24. doi: 10.1586/1744666X.2014.967684. PubMed PMID: 25340427; PubMed Central PMCID: PMC4332833. 
7. Ziegler SF, Roan F, Bell BD, Stoklasek TA, Kitajima M, Han H. The biology of thymic stromal lymphopoietin (TSLP). Adv Pharmacol. 2013;66:129-55. Epub 2013/02/26. doi: 10.1016/B978-0-12-404717-4.00004-4. PubMed PMID: 23433457; PubMed Central PMCID: PMC4169878.

8. Wohlmann A, Sebastian K, Borowski A, Krause S, Friedrich K. Signal transduction by the atopy-associated human thymic stromal lymphopoietin (TSLP) receptor depends on Janus kinase function. Biol Chem. 2010;391(2-3):181-6. PubMed PMID: 20128689.

9. Ying S, O'Connor B, Ratoff J, Meng Q, Mallett K, Cousins D, et al. Thymic stromal lymphopoietin expression is increased in asthmatic airways and correlates with expression of Th2-attracting chemokines and disease severity. J Immunol. 2005;174(12):8183-90. PubMed PMID: 15944327.

10. Zhou B, Comeau MR, De Smedt T, Liggitt HD, Dahl ME, Lewis DB, et al. Thymic stromal lymphopoietin as a key initiator of allergic airway inflammation in mice. Nat Immunol. 2005;6(10):1047-53. PubMed PMID: 16142237.

11. Hener P, Friedmann L, Metzger D, Chambon P, Li M. Aggravated TSLP-induced atopic dermatitis in mice lacking Dicer in adult skin keratinocytes. J Invest Dermatol. 2011;131(11):2324-7. doi: http://www.nature.com/jid/journal/v131/n11/suppinfo/jid2011208s1.html.

12. Stenmark KR, Fagan KA, Frid MG. Hypoxia-induced pulmonary vascular remodeling: Cellular and molecular mechanisms. Circ Res. 2006;99(7):675-91. doi: 10.1161/01.RES.0000243584.45145.3f. 
13. Voelkel NF, Tuder RM. Hypoxia-induced pulmonary vascular remodeling: a model for what human disease? J Clin Invest. 2000;106(6):733-8. Epub 2000/09/21. doi: 10.1172/JCI11144. PubMed PMID: 10995781; PubMed Central PMCID: PMC381402.

14. Christou H, Morita T, Hsieh C-M, Koike H, Arkonac B, Perrella MA, et al. Prevention of hypoxia-induced pulmonary hypertension by enhancement of endogenous heme oxygenase1 in the rat. Circ Res. 2000;86(12):1224-9. doi: 10.1161/01.res.86.12.1224.

15. Higenbottam T, Cremona G. Acute and chronic hypoxic pulmonary hypertension. Eur Respir J. 1993;6(8):1207-12.

16. Stenmark KR, Tuder RM, El Kasmi KC. Metabolic reprogramming and inflammation act in concert to control vascular remodeling in hypoxic pulmonary hypertension. J Appl Physiol (1985). 2015;119(10):1164-72. Epub 2015/05/02. doi: 10.1152/japplphysiol.00283.2015. PubMed PMID: 25930027; PubMed Central PMCID: PMC4816410.

17. Pugliese SC, Poth JM, Fini MA, Olschewski A, El Kasmi KC, Stenmark KR. The role of inflammation in hypoxic pulmonary hypertension: from cellular mechanisms to clinical phenotypes. Am J Physiol Lung Cell Mol Physiol. 2015;308(3):L229-52. Epub 2014/11/25. doi: 10.1152/ajplung.00238.2014. PubMed PMID: 25416383; PubMed Central PMCID: PMC4338929.

18. Tuder RM, Archer SL, Dorfmuller P, Erzurum SC, Guignabert C, Michelakis E, et al. Relevant issues in the pathology and pathobiology of pulmonary hypertension. $\mathrm{J}$ Am Coll Cardiol. 2013;62(25 Suppl):D4-12. Epub 2013/12/21. doi: 10.1016/j.jacc.2013.10.025. PubMed PMID: 24355640; PubMed Central PMCID: PMC3970402.

19. Bärtsch P, Gibbs JSR. Effect of Altitude on the Heart and the Lungs. Circulation. 2007;116(19):2191-202. doi: 10.1161/circulationaha.106.650796. 
20. Eldridge MW, Braun RK, Yoneda KY, Walby WF. Effects of altitude and exercise on pulmonary capillary integrity: evidence for subclinical high-altitude pulmonary edema. J Appl Physiol (1985). 2006;100(3):972-80. doi: 10.1152/japplphysiol.01048.2005.

21. Anglesio MS, George J, Kulbe H, Friedlander M, Rischin D, Lemech C, et al. IL6-STAT3HIF signaling and therapeutic response to the angiogenesis inhibitor sunitinib in ovarian clear cell cancer. Clin Cancer Res. 2011;17(8):2538-48. doi: 10.1158/1078-0432.ccr-103314.

22. Yokoe T, Minoguchi K, Matsuo H, Oda N, Minoguchi H, Yoshino G, et al. Elevated levels of C-reactive protein and interleukin-6 in patients with obstructive sleep apnea syndrome are decreased by nasal continuous positive airway pressure. Circulation. 2003;107(8):1129-34. doi: 10.1161/01.cir.0000052627.99976.18.

23. Hartmann G, Tschöp M, Fischer R, Bidlingmaier C, Riepl R, Tschöp K, et al. High altitude increases circulating interleukin-6, interleukin-1 receptor antagonist and C-reactive protein. Cytokine. 2000;12(3):246-52. doi: http://dx.doi.org/10.1006/cyto.1999.0533.

24. Elson DA, Thurston G, Huang LE, Ginzinger DG, McDonald DM, Johnson RS, et al. Induction of hypervascularity without leakage or inflammation in transgenic mice overexpressing hypoxia-inducible factor-1alpha. Genes Dev. 2001;15(19):2520-32. Epub 2001/10/03. doi: 10.1101/gad.914801. PubMed PMID: 11581158; PubMed Central PMCID: PMC312791.

25. Eltzschig HK, Carmeliet P. Hypoxia and Inflammation. N Engl J Med. 2011;364(7):656-65. doi: doi:10.1056/NEJMra0910283.

26. Dorfmüller P, Perros F, Balabanian K, Humbert M. Inflammation in pulmonary arterial hypertension. Eur Respir J. 2003;22(2):358-63. doi: 10.1183/09031936.03.00038903. 
27. Humbert M, Monti G, Brenot F, Sitbon O, Portier A, Grangeot-Keros L, et al. Increased interleukin-1 and interleukin-6 serum concentrations in severe primary pulmonary hypertension. Am J Respir Crit Care Med. 1995;151(5):1628-31.

28. Tuder RM, Voelkel NF. Pulmonary hypertension and inflammation. J Lab Clin Med. 1998;132(1):16-24.

29. Steiner MK, Syrkina OL, Kolliputi N, Mark EJ, Hales CA, Waxman AB. Interleukin-6 overexpression induces pulmonary hypertension. Circ Res. 2009;104(2):236-44. doi: 10.1161/circresaha.108.182014.

30. Sanchez O, Sitbon O, Jaïs X, Simonneau Gr, Humbert M. Immunosuppressive therapy in connective tissue diseases-associated pulmonary arterial hypertension*. CHEST J. 2006;130(1):182-9. doi: 10.1378/chest.130.1.182.

31. Hartman W, Helan M, Smelter D, Sathish V, Thompson M, Pabelick CM, et al. Role of hypoxia-induced brain derived neurotrophic factor in human pulmonary artery smooth muscle. PLoS One. 2015;10(7):e0129489. Epub 2015/07/21. doi: 10.1371/journal.pone.0129489. PubMed PMID: 26192455; PubMed Central PMCID: PMC4507987.

32. Helan M, Aravamudan B, Hartman WR, Thompson MA, Johnson BD, Pabelick CM, et al. BDNF secretion by human pulmonary artery endothelial cells in response to hypoxia. $\mathrm{J}$ Mol Cell Cardiol. 2014;68:89-97. Epub 2014/01/28. doi: 10.1016/j.yjmcc.2014.01.006. PubMed PMID: 24462831; PubMed Central PMCID: PMC3977651.

33. Meuchel LW, Thompson MA, Cassivi SD, Pabelick CM, Prakash YS. Neurotrophins induce nitric oxide generation in human pulmonary artery endothelial cells. Cardiovasc Res. 
2011;91(4):668-76. Epub 2011/04/19. doi: 10.1093/cvr/cvr107. PubMed PMID: 21498417;

PubMed Central PMCID: PMC3156903.

34. van Beijnum JR, Rousch M, Castermans K, van der Linden E, Griffioen AW. Isolation of endothelial cells from fresh tissues. Nat Protocols. 2008;3(6):1085-91. Epub 2008/06/13. PubMed PMID: 18546599.

35. Abcejo A, Venkatachalem S, Aravamudan B, Meuchel L, Thompson M, Pabelick C, et al. Brain-derived neurotrophic factor enhances calcium regulatory mechanisms in human airway smooth muscle. PLoS One. 2012;7(8):e44343. Epub 2012/09/07. doi: 10.1371/journal.pone.0044343. PubMed PMID: 22952960; PubMed Central PMCID: PMC3430656.

36. Meuchel LW, Thompson MA, Cassivi SD, Pabelick CM, Prakash YS. Neurotrophins induce nitric oxide generation in human pulmonary artery endothelial cells. Cardiovasc Res. 2011;91(4):668-76. doi: 10.1093/cvr/cvr107.

37. Redhu NS, Saleh A, Halayko AJ, Ali AS, Gounni AS. Essential role of NF-кB and AP-1 transcription factors in TNF- $\alpha$-induced TSLP expression in human airway smooth muscle cells. Am J Physiol Lung Cell Mol Physiol. 2011;300(3):L479-L85. doi: 10.1152/ajplung.00301.2009.

38. Harada M, Hirota T, Jodo AI, Doi S, Kameda M, Fujita K, et al. Functional analysis of the thymic stromal lymphopoietin variants in human bronchial epithelial cells. Am J Respir Cell Mol Biol. 2009;40(3):368-74. Epub 2008/09/13. doi: 10.1165/rcmb.2008-0041OC. PubMed PMID: 18787178.

39. Zhang K, Shan L, Rahman MS, Unruh H, Halayko AJ, Gounni AS. Constitutive and inducible thymic stromal lymphopoietin expression in human airway smooth muscle cells: 
role in chronic obstructive pulmonary disease. Am J Physiol Lung Cell Mol Physiol. 2007;293(2):L375-L82. doi: 10.1152/ajplung.00045.2007.

40. Jang Y, Jeong SH, Park YH, Bae HC, Lee H, Ryu WI, et al. UVB induces HIF-1alphadependent TSLP expression via the JNK and ERK pathways. J Invest Dermatol. 2013;133(11):2601-8. Epub 2013/05/04. doi: 10.1038/jid.2013.203. PubMed PMID: 23639975.

41. Courboulin A, Paulin R, Giguere NJ, Saksouk N, Perreault T, Meloche J, et al. Role for miR204 in human pulmonary arterial hypertension. J Exp Med. 2011;208(3):535-48. Epub 2011/02/16. doi: 10.1084/jem.20101812. PubMed PMID: 21321078; PubMed Central PMCID: PMC3058572.

42. Li M, Liu Y, Dutt P, Fanburg BL, Toksoz D. Inhibition of serotonin-induced mitogenesis, migration, and ERK MAPK nuclear translocation in vascular smooth muscle cells by atorvastatin. Am J Physiol Lung Cell Mol Physiol. 2007;293(2):L463-L71. doi: 10.1152/ajplung.00133.2007.

43. BelAiba RS, Bonello S, Zähringer C, Schmidt S, Hess J, Kietzmann T, et al. Hypoxia upregulates hypoxia-inducible factor-1 $\alpha$ transcription by involving phosphatidylinositol 3kinase and nuclear factor $\mathrm{\kappa B}$ in pulmonary artery smooth muscle cells. Mol Biol Cell. 2007;18(12):4691-7. doi: 10.1091/mbc.E07-04-0391.

44. Quentmeier H, Drexler HG, Fleckenstein D, Zaborski M, Armstrong A, Sims JE, et al. Cloning of human thymic stromal lymphopoietin (TSLP) and signaling mechanisms leading to proliferation. Leukemia. 2001;15(8):1286-92. PubMed PMID: 11480573.

45. Bae CH, Choi YS, Song SY, Kim YD. Effect of thymic stromal lymphopoietin on MUC5B expression in human airway epithelial cells. Biochem Biophys Res Commun. 
2014;448(2):231-5. Epub 2014/05/06. doi: 10.1016/j.bbrc.2014.04.100. PubMed PMID: 24792379.

46. Zhong J, Sharma J, Raju R, Palapetta SM, Prasad TS, Huang TC, et al. TSLP signaling pathway map: a platform for analysis of TSLP-mediated signaling. Database (Oxford). 2014;2014:bau007. Epub 2014/02/28. doi: 10.1093/database/bau007. PubMed PMID: 24573880 ; PubMed Central PMCID: PMC3935308.

47. Mascarenhas JO, Cross NC, Mesa RA. The future of JAK inhibition in myelofibrosis and beyond. Blood Rev. 2014;28(5):189-96. Epub 2014/07/22. doi: 10.1016/j.blre.2014.06.002. PubMed PMID: 25043171.

48. Sacks RS, Firth AL, Remillard CV, Agange N, Yau J, Ko EA, et al. Thrombin-mediated increases in cytosolic $[\mathrm{Ca} 2+]$ involve different mechanisms in human pulmonary artery smooth muscle and endothelial cells. Am J Physiol Lung Cell Mol Physiol. 2008;295(6):L1048-L55. doi: 10.1152/ajplung.90259.2008.

49. Guilluy C, Sauzeau V, Rolli-Derkinderen M, Guerin P, Sagan C, Pacaud P, et al. Inhibition of RhoA/Rho kinase pathway is involved in the beneficial effect of sildenafil on pulmonary hypertension. $\mathrm{Br}$ J Pharmacol. 2005;146(7):1010-8. Epub 2005/10/06. doi: 10.1038/sj.bjp.0706408. PubMed PMID: 16205723; PubMed Central PMCID: PMC1751229. 


\section{Figure Legends.}

Figure 1. Thymic stromal lymphopoeitin (TSLP) and receptor (TSLP-R) expression and secretion in human pulmonary artery endothelial cells (PAECs) and smooth muscle cells (PASMCs). A) Immunofluorescent staining of PAECs and PASMCs demonstrate the presence of TSLP and TSLP-R. Primary (not shown) and Alexa 555 secondary antibody controls reveal only DAPI staining of cell nuclei and establish antibody specificity. B) Extracellular TSLP was measured by ELISA and shows release of TSLP by both PAECs and PASMCs during normoxia. In PAECs, TSLP release was significantly enhanced following $72 \mathrm{~h}$ of $1 \%$ hypoxia. Hypoxia did not appear to influence PASMC TSLP release. (Values are means \pm SE. * indicates significant $(p<0.05)$ effect compared to control, $\mathrm{n}=5-8$ )

Figure 2. Effect of hypoxia on TSLP and TSLP-R expression in PAECs and PASMCs. A) PAECs exposed to hypoxia for $72 \mathrm{~h}$ showed significant upregulation of TSLP expression in comparison to normoxia controls. In contrast, TSLP expression in PASMCs following $72 \mathrm{~h}$ hypoxia was unchanged. B) Western analysis showed significant upregulation of TSLP-R expression in PAECs in comparison to normoxia controls. Similarly, TSLP-R expression in PASMCs was increased following hypoxia exposure for $72 \mathrm{~h}$. (Values are means \pm SE. * indicates significant $(\mathrm{p}<0.05)$ effect compared to normoxia control, $n=4$ each)

Figure 3. Proliferation of PASMCs. Both hypoxia and TSLP (20 ng/ml; 72h) promote robust cellular proliferation which can be attenuated by inhibition of HIF inhibitor or STAT3 (LLL12) $(10 \mu \mathrm{M}$ each). See methods for proliferation assay. (Values are means \pm SE. * indicates significant 
$(\mathrm{p}<0.05)$ effect compared to normoxia control, \# compared to hypoxia control; $\$$ compared to normoxia TSLP treatment; \& compared to hypoxia TSLP treatment; $n=4$ each)

Figure 4. Proliferation of PASMCs in response to hypoxia and/or TSLP. A) Western blot analysis of PASMCs demonstrates upregulation of Cyclin E following TSLP or hypoxia compared to normoxia control. HIF inhibitor and LLL12 in the presence of TSLP significantly blunted increased expression of Cyclin E under normoxia and hypoxia compared to TSLP alone in each condition. B) PCNA expression was also increased with TSLP and hypoxia exposure. HIF inhibitor and LLL12 significantly prevented PCNA upregulation in the presence of TSLP during hypoxia only. (Values are means \pm SE. * indicates significant $(\mathrm{p}<0.05)$ effect compared to normoxia control, \$ compared to normoxia TSLP treatment; \& compared to hypoxia TSLP treatment; $\mathrm{n}=5$ )

Figure 5. Effects of TSLP on MAPK and PI3K/Akt pathways. A) Western analysis of PASMCs shows increased expression of Akt when exposed to TSLP in normoxia, and hypoxia alone. HIF inhibitor significantly blunted Akt upregulation compared to hypoxia+TSLP treatment. B) Evaluation of PI3K via Western analysis demonstrates significantly increased expression with TSLP in normoxia, and hypoxia alone, an effect blunted by HIF inhibitor compared to TSLP treatment in normoxia and hypoxia . LLL12 prevented PI3K upregulation during hypoxia+TSLP only. C) and D) ERK 1 and ERK2 expression is not significantly altered by hypoxia or in the presence of TSLP in normoxia or hypoxia. LLL12 treatment significantly inhibited ERK1/2 expression in the presence of TSLP during hypoxia. (Values are means \pm SE. $\$$ indicates 
significant $(\mathrm{p}<0.05)$ effect compared to normoxia TSLP treatment; \& compared to hypoxia TSLP treatment; $n=5-6$ )

Figure 6. TSLP activates Jak2/STAT3 pathway in PASMCs. A) Western blots of human PASMCs exposed to normoxia, hypoxia, TSLP and inhibitors as previously stated show that hypoxia enhances JAK2 expression compared to normoxia control. TSLP increased JAK2 expression in normoxic conditions but did not potentiate the effects of hypoxia. HIF inhibitor and LLL12 significantly decreased JAK2 expression in the presence of TSLP during normoxia but only LLL12 treatment had significant effects on JAK2 expression compared to TSLP+hypoxia exposure. B) Analysis of STAT3 expression via Western blot show significantly increased expression of STAT3 in normoxic conditions with TSLP and hypoxia alone. LLL12 in the presence of TSLP significantly reduced STAT3 expression compared to TSLP alone. HIF inhibitor and LLL12 substantially reduced STAT3 expression in the presence of TSLP compared to hypoxia+TSLP. (Values are means \pm SE. * indicates significant $(\mathrm{p}<0.05)$ effect compared to normoxia control, \& compared to hypoxia TSLP treatment; $n=6$ )

Figure 7. Effect of TSLP on PASMC intracellular calcium $\left(\left[\mathrm{Ca}^{2+}\right]_{\mathrm{i}}\right)$ responses to agonist. Exposure to hypoxia and/or TSLP for $72 \mathrm{~h}$ results in increased $\left[\mathrm{Ca}^{2+}\right]_{\mathrm{i}}$ responses to serotonin $(10 \mu \mathrm{M})$ : effects blunted by HIF inhibitor under both normoxic and hypoxic conditions (Values are means \pm SE. * indicates significant $(\mathrm{p}<0.05)$ effect compared to normoxia control, \# compared to hypoxia control; \$ compared to normoxia TSLP treatment; \& compared to hypoxia TSLP treatment; n=4) 
Figure 8. Schematic of TSLP expression and effect in pulmonary artery. TSLP can be derived from PAECs (largely) and PASMCs, with influence on TSLPR expressed by both cell types. Hypoxia enhances PAEC-derived TSLP as well as TSLP-R in both cell types, thus enhancing the potential for TSLP effect. TSLP acts on PASMCs to enhance cell proliferation and calcium responses to agonist (and thus contractility). TSLP may interact with hypoxia by promoting HIF1$\alpha$ signaling: effects relevant to diseases such as pulmonary hypertension. 


\section{Figure 1}

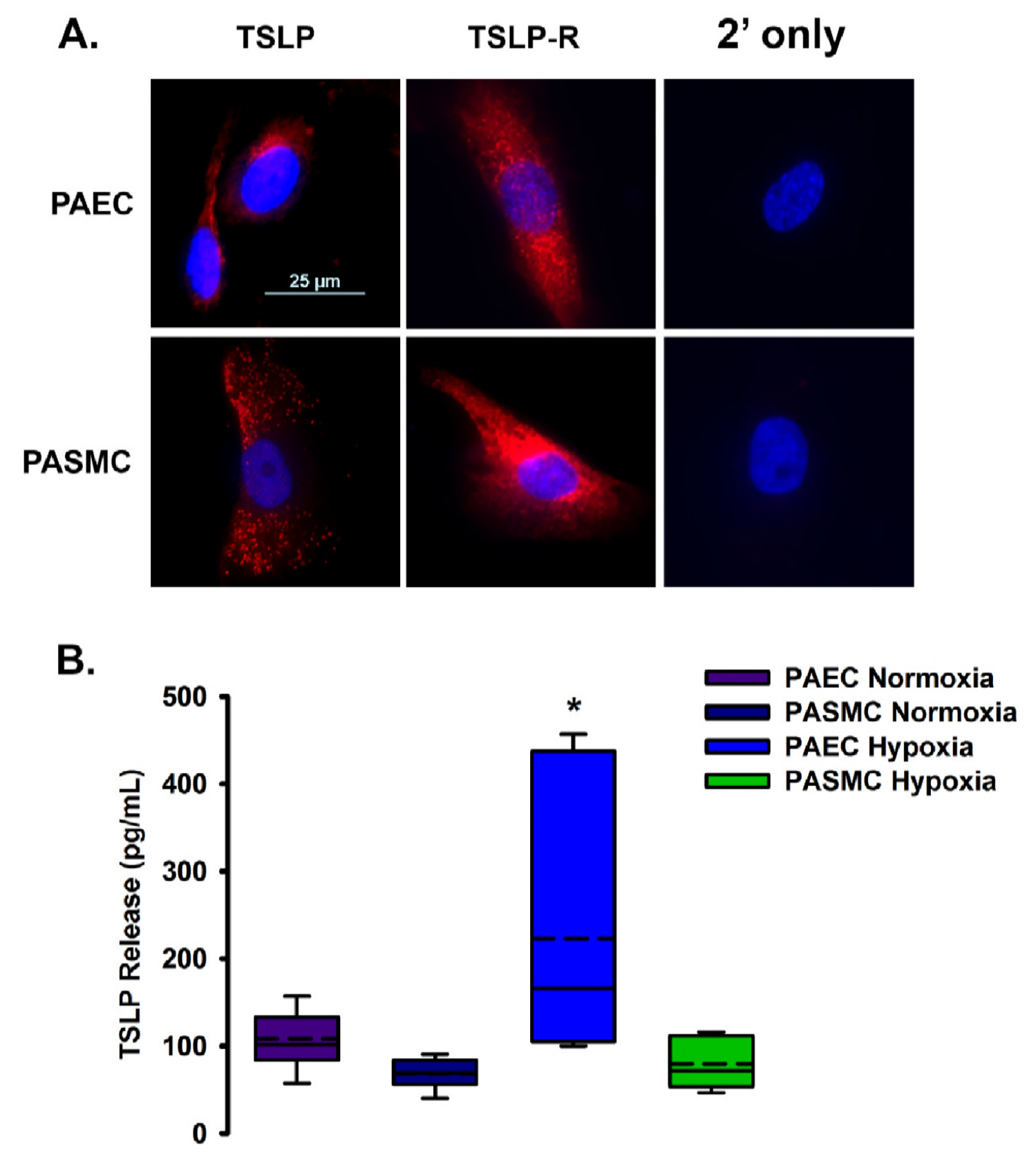




\section{Figure 2}

A.

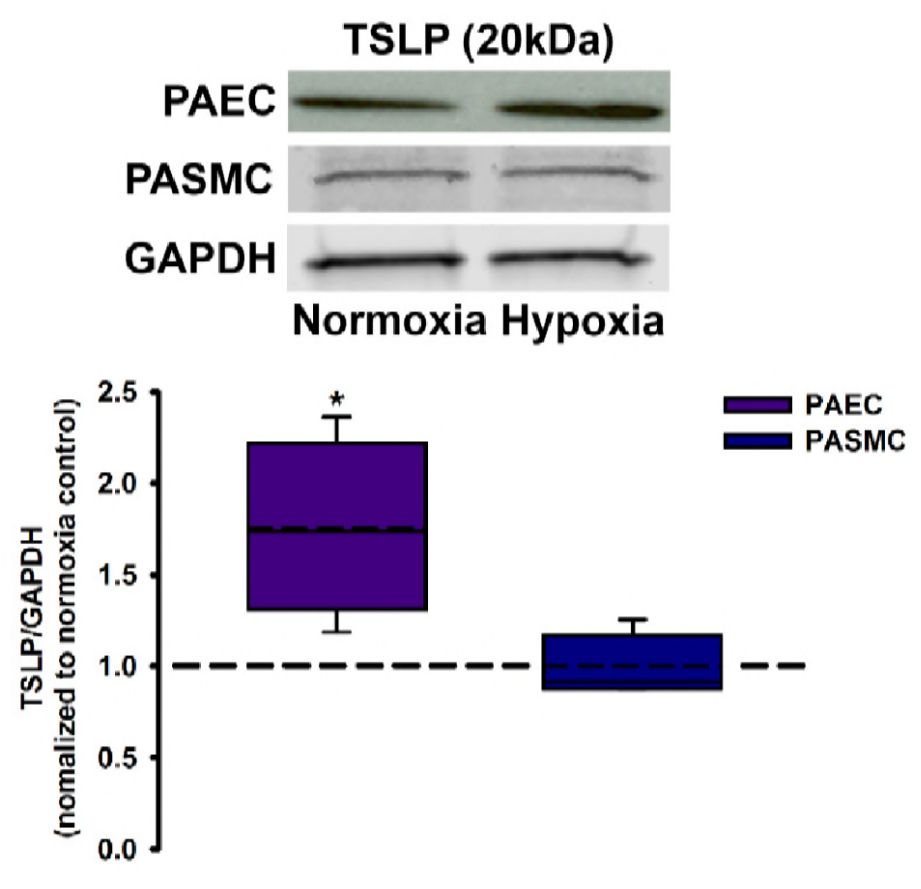

B.

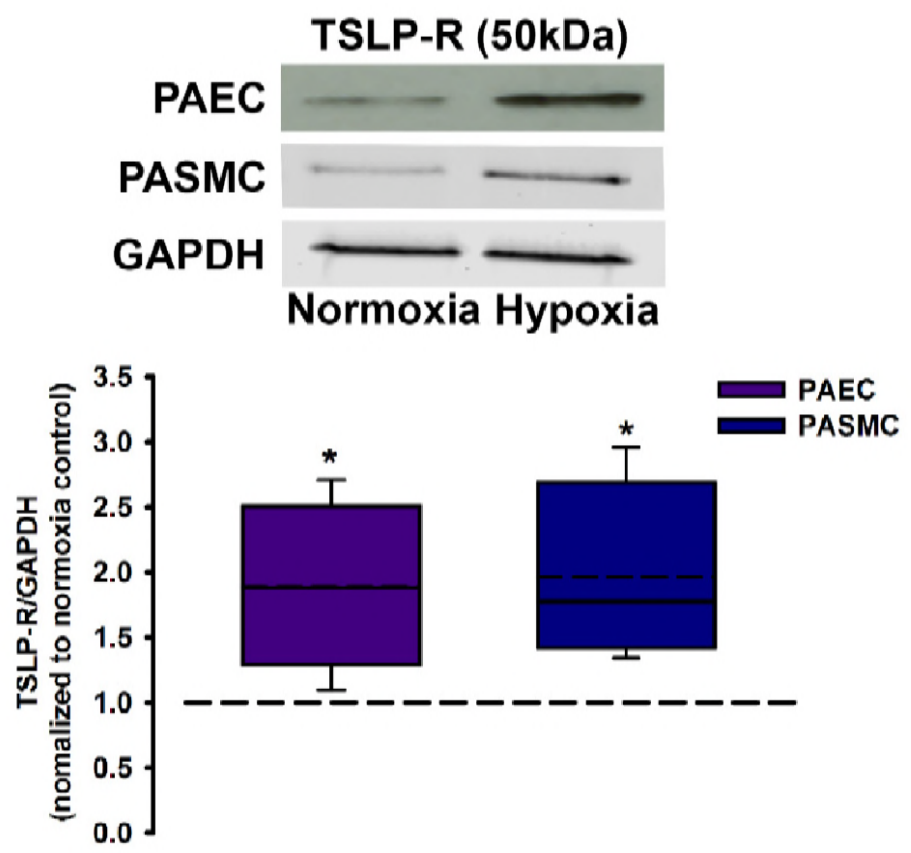




\section{Figure 3}

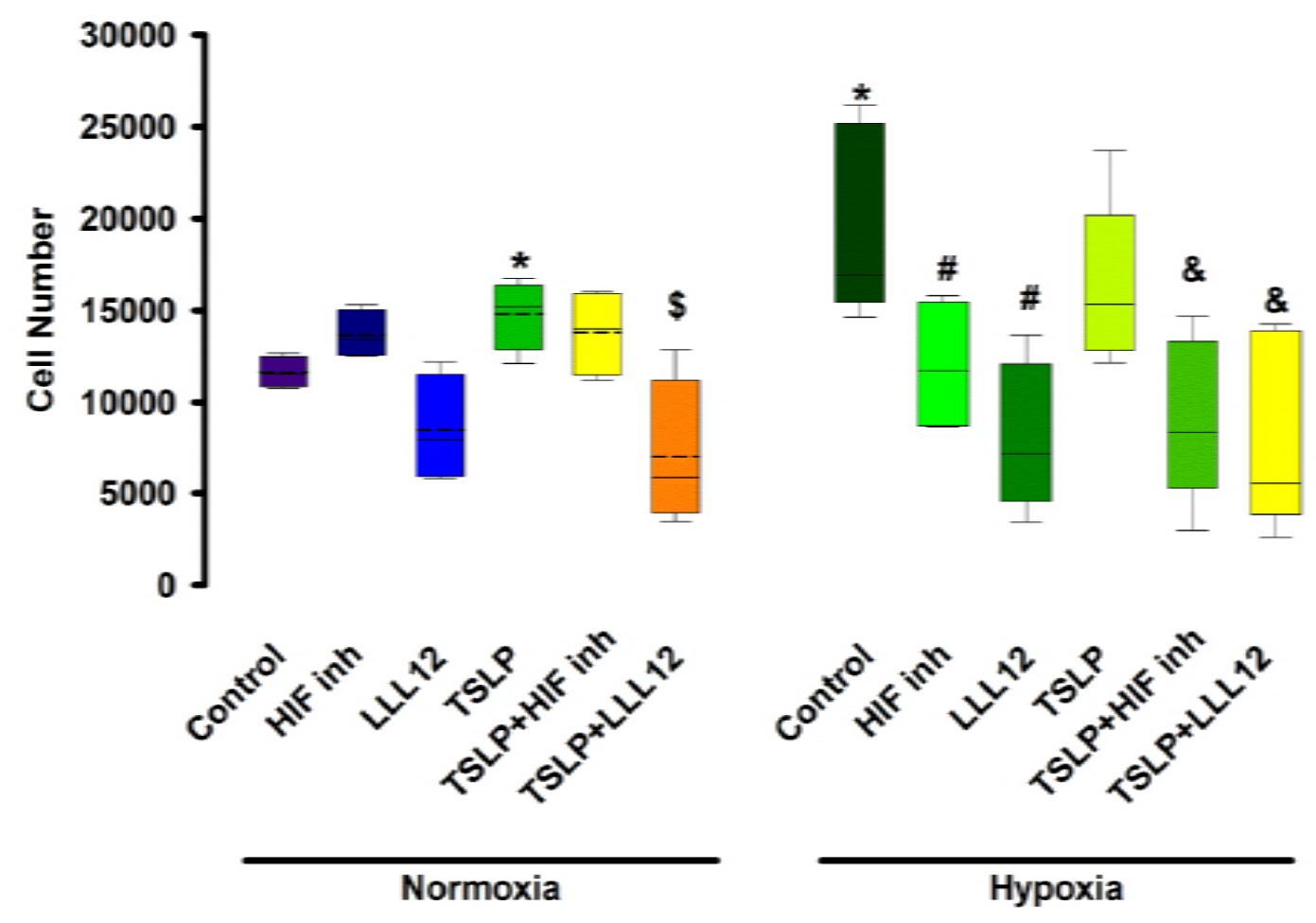




\section{Figure 4}

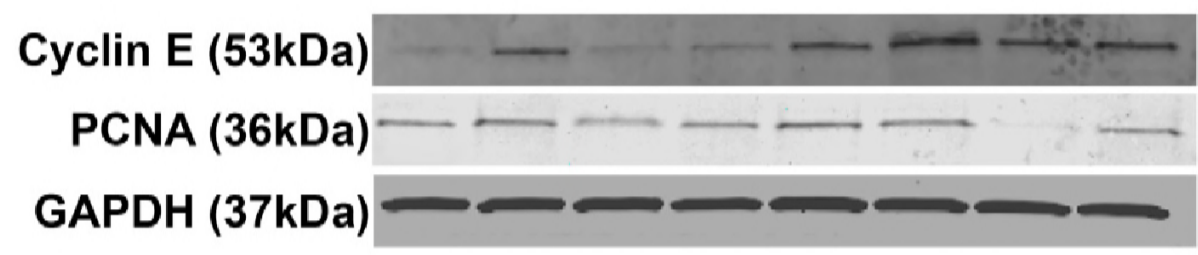

A.

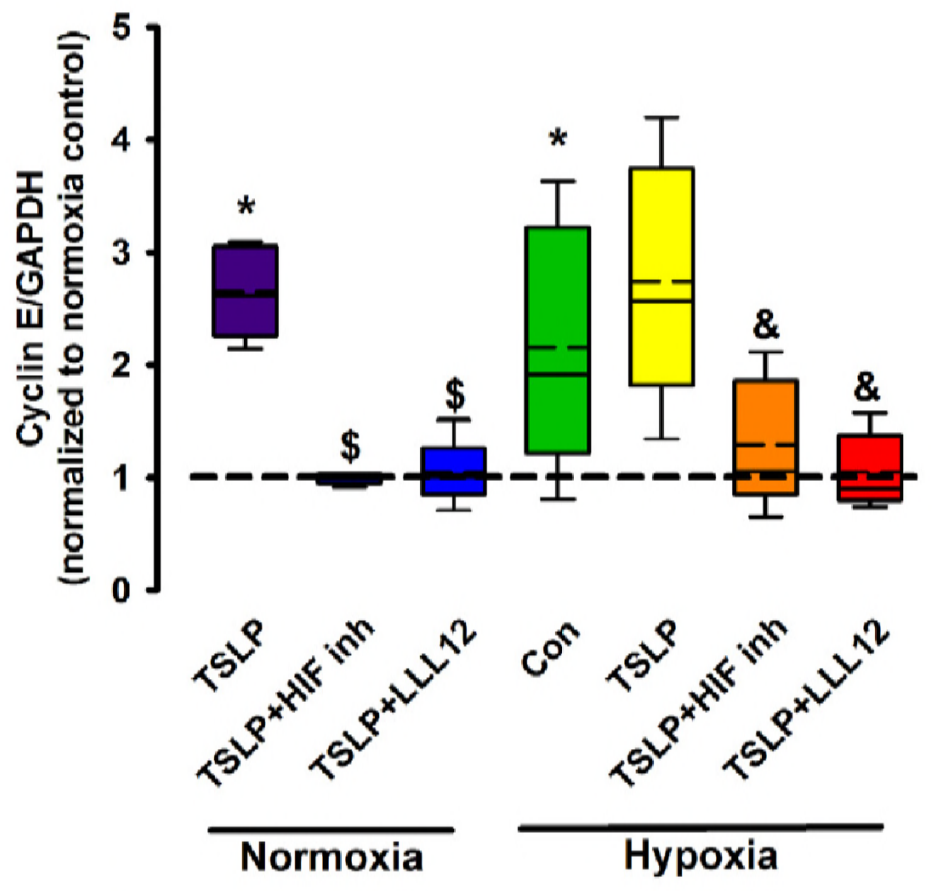

B.

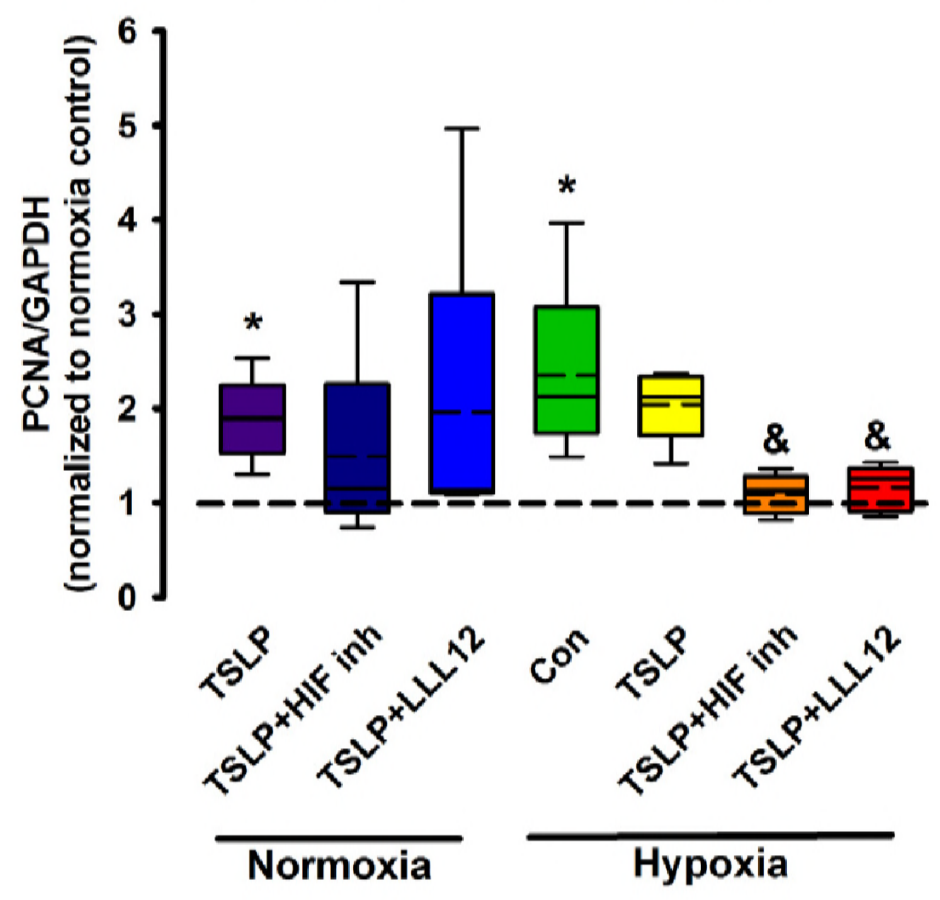


Figure 5

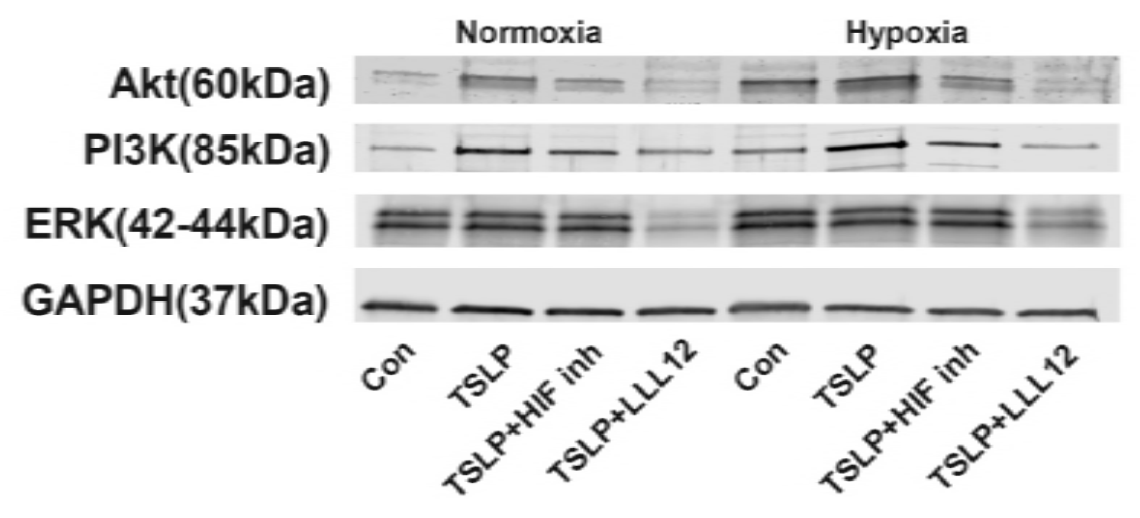

A.

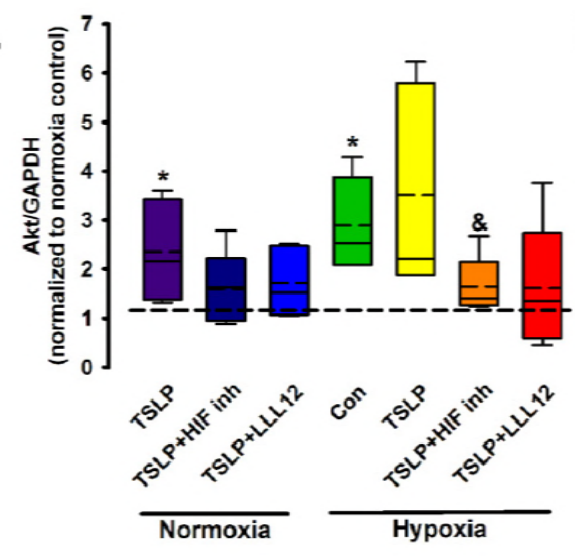

B.

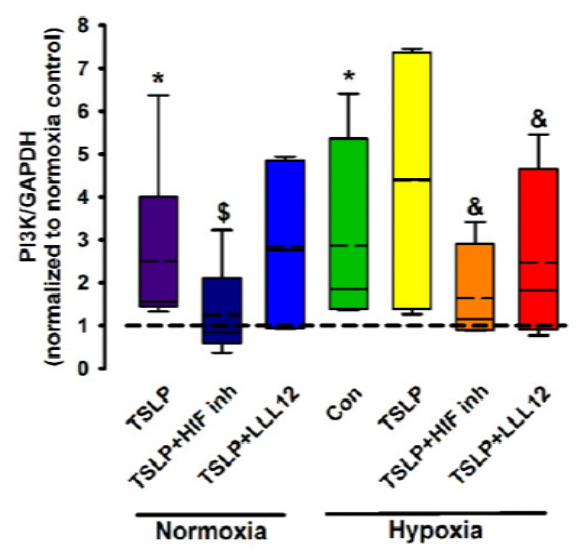

D.

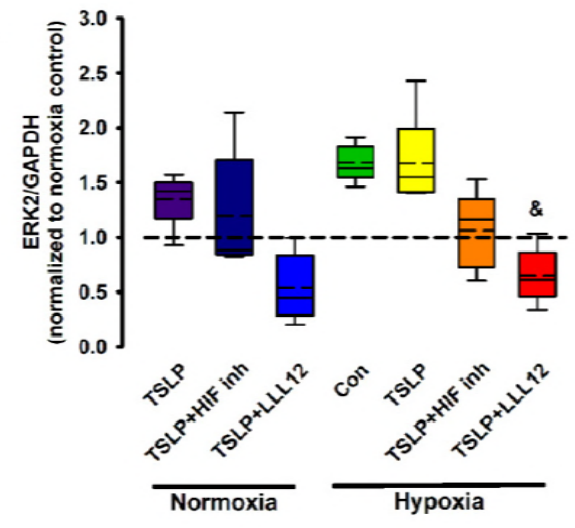




\section{Figure 6}
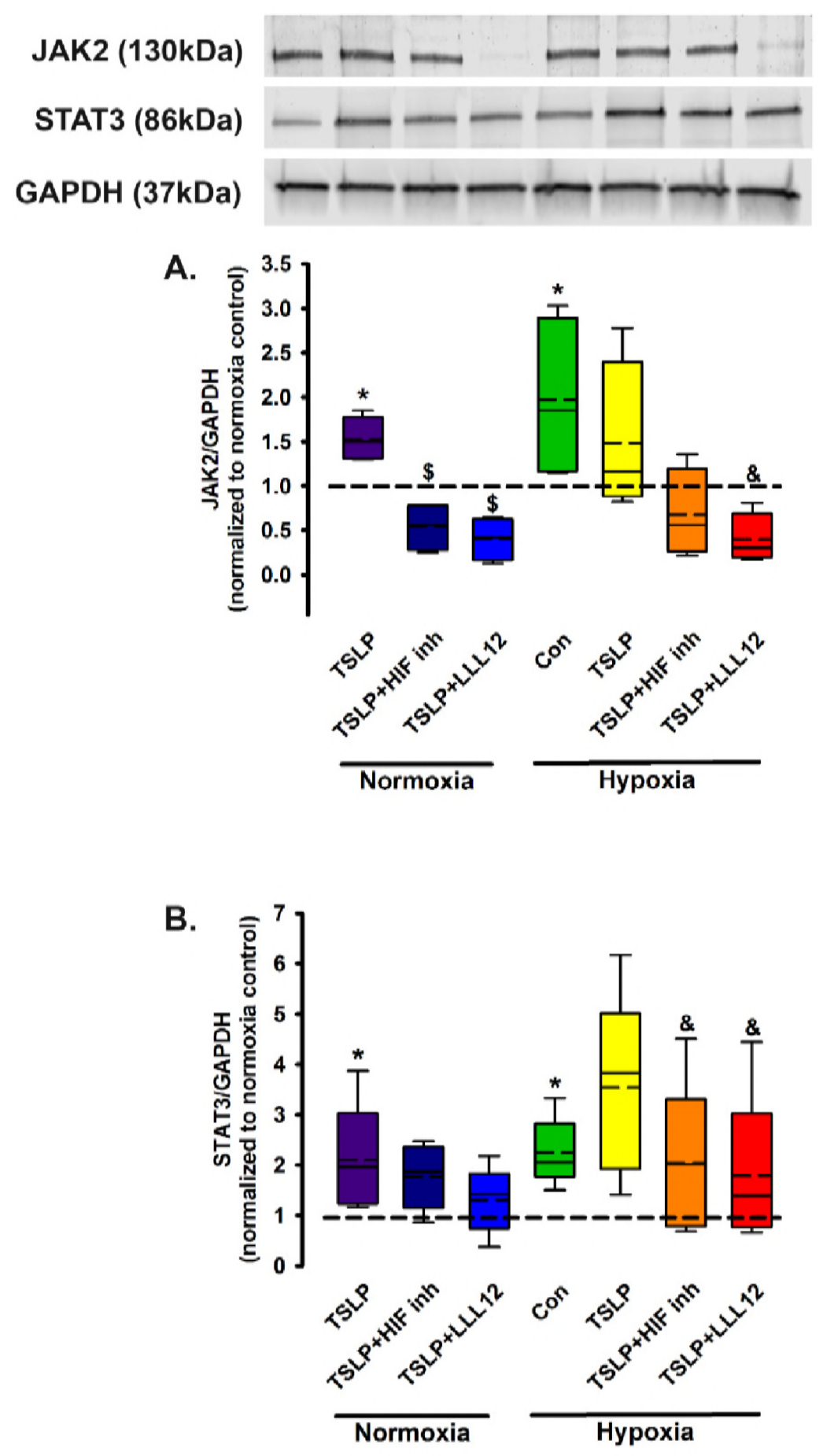

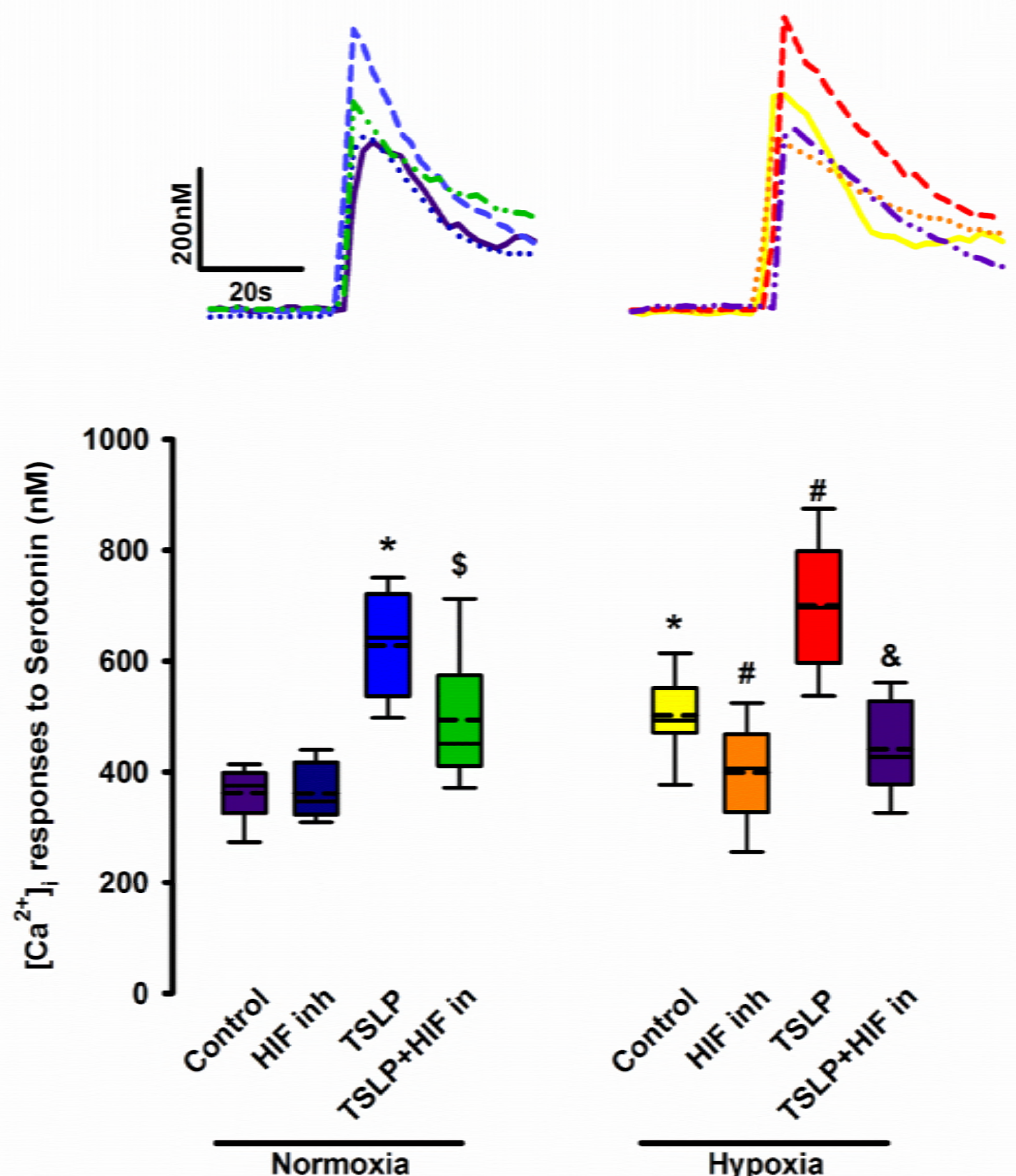

Hypoxia 
bioRxiv preprint doi: https://doi.org/10.1101/441188; this version posted October 11,2018 . The copyright holder for this preprint (which was not certified by peer review) is the author/funder, who has granted bioRxiv a license to display the preprint in perpetuity. It is made available under aCC-BY 4.0 International license.

\section{Figure 8}

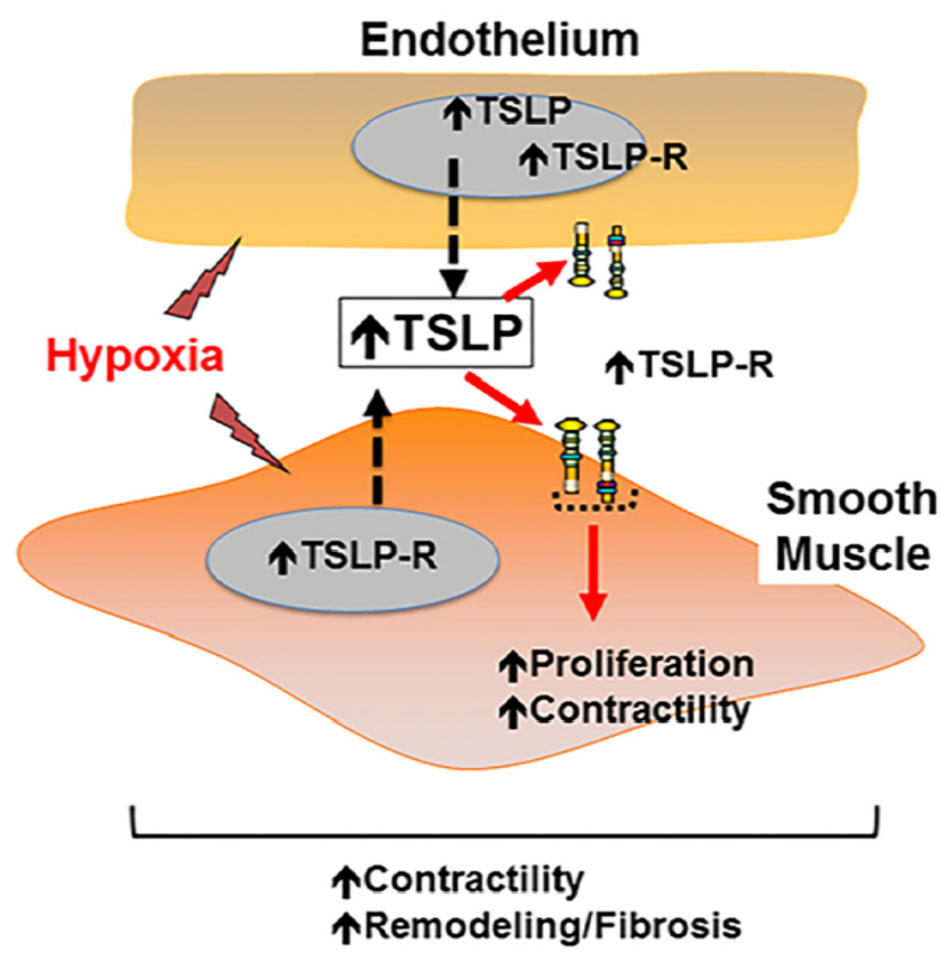

